\title{
The association between substance abuse and HIV infection among people visiting HIV counseling and testing centers in Addis Ababa, Ethiopia
}

\author{
Assefa Seme ${ }^{1}$, Damen Haile Mariam², Alemayehu Worku ${ }^{2}$
}

\begin{abstract}
Background: The magnitude of HIV/AIDS in Ethiopia is ever increasing. It is also believed that the use of substances is increasing in some major towns including Addis Ababa. However, data regarding the relation of substance abuse and HIV infection is lacking.

Objective: A case-control study was carried out in Addis Ababa to explore the association between substance abuse and HIV infection and to determine factors related to substance abuse among people visiting HIV counseling and testing centers.

Methods: Cases and controls were compared by socio demographic, socio economic, exposure to substances and risky behaviors that predispose them to HIV infection.

Result: In the study, alcohol drinking was found to be associated with serum HIV positivity. While young age of 15 to 24 years and being single were found to be associated with serum HIV positivity, having income was found to be protective. Being male and having sex with commercial sex workers were related to both alcohol drinking and khat chewing.

Conclusion and recommendations: Alcohol was found to be a significant risk factor for HIV infection in the study population. The need for health education to bring about behavioral changes and further study to identify the prevalence and role of substance in exposure to HIV infection in the community is recommended. [Ethiop.J.Health Dev. 2005;19(2):116-125]
\end{abstract}

\begin{abstract}
Introduction
AIDS is today a major threat to the world's population- to its overall social, economic, and political well being, as well as to the individual health of hundreds of millions of people. It has became the most devastating disease humankind has ever seen. More than 60 million people have been infected with the virus since the epidemic began (1).
\end{abstract}

The most recent UNAIDS/WHO estimate shows that, in 2001 alone, 5 million people were newly infected with HIV of which 3.4 million infections were in Africa. More than $70 \%$ of the people living with HIV/AIDS, $78 \%$ of active AIDS cases and 68\% of new infections have occurred in Sub-Saharan Africa. More than $80 \%$ of the women worldwide and $87 \%$ of children infected with HIV/AIDS are in sub Saharan Africa, as are $95 \%$ of the world's AIDS orphans. Similarly, 2.3 million deaths due to HIV/AIDS were in Africa $(1,2)$.

Ethiopia is one of the Sub-Saharan African countries where there is high rate of HIV/AIDS infection next to South Africa and Nigeria. In the year 2000, it was estimated that there were about 2.6 million people infected with HIV (3).

It has been reported in many different studies that HIV/AIDS infection is common among substance abusers in the western world. Drug abuse is one of the primary ways of HIV spread. More than $5 \%$ of all HIV infections are related to injecting drug use with infected needles. In many parts of the world, excluding Africa, injecting drug use is fast becoming one of the main modes of HIV transmission (4).

In the Russian Federation, more than half of all reported cases of HIV/AIDS to date have been injecting drug users. However, the risk of HIV transmission is not limited to drugs that are injected. Drugs, that can be swallowed or inhaled, normally alter people's judgment, and can lead to risky sexual behaviors, such as unprotected sex, having multiple sexual partners and prolonged and traumatic sex, which can also result in HIV transmission $(4,5)$.

Though many African countries are on drug transit routes, the extent of drug-related problems in Africa is not clear. Though drug use does not appear to be a major public health problem for much of Africa, a number of hospital admissions for drug-associated problems have recently increased in some cities. In Nigeria, for example, heroin and cocaine related problems have been highlighted in a number of reports (6). International drug traffickers are currently importing a broad range of drugs to many African countries. Of more importance, how ever, is the rapidly increasing use of alcohol in SubSaharan Africa, which is associated with a loss of sexual inhibition. In a study conducted on women who were

${ }^{1}$ Health Service and Training Department, Oromia Health Bureau; ${ }^{2}$ Department of Community Health, Faculty of Medicine, Addis Ababa, University, Addis Ababa, Ethiopia 
abused by their spouses, $69 \%$ identified alcohol/drug abuse as the main cause of conflict leading to abuse. On the other hand, sexually transmitted diseases were identified to be higher among drinkers than non-drinkers in patients seen at Harare's primary health clinic $(6,7,8)$.

In Ethiopia, the four important transmission mechanisms for HIV are sexual contact, peri-natal transmissions, blood transfusions, and unsafe injections (3). Even though the problem of substance abuse (including drug abuse) is reported to be on the increase in major urban areas of Ethiopia, the available data on the relation of substance abuse and HIV status is minimal. Therefore, this study was conducted to explore the association between substance abuse and HIV infection among people visiting HIV counseling and testing (HIVCT) centers in Addis Ababa.

\section{Methods}

A case-control study to determine the association between substance abuse and HIV infection among people visiting HIV counseling and testing centers was conducted in 2001 in Addis Ababa, the capital city of Ethiopia. The total population of the city is estimated to be about 2,570,000 in 2001 among which the number of population aged fifteen years and above is 1.4 million. Males constitute $48 \%$ of the total population, the male to female ratio being about 1: 1.1. Addis Ababa has 18 hospitals, 24 health centers, 161 health stations, 340 clinics and 47 health posts run by government, private, and non-governmental organizations (NGOs) with a potential health service coverage of $93.4 \%$ in 2001 . The clinics are sub categorized as small, medium, higher, and special. There are 114 small (lower), 94 medium, 66 higher and 66 special clinics. There are few clinics, which are officially licensed by the Region 14 Health Bureau to carry out HIV counseling and testing activities. These are clinics, which fulfill the criteria set by the Regional Health Bureau.

All health institutions that are officially licensed by Region 14 Health Bureau to carry out HIV counseling and testing were listed and stratified on the basis of ownership as private, government and NGO owned health institutions. All the centers that were licensed by Region 14 Health Bureau to carry out HIV counseling and testing during the study period, except three of them which were excluded from the study because of refusal and low case load, were part of the study. Therefore, two NGO higher clinics, two government hospitals, one government health center, and three private higher clinics were included in the study. Both cases and controls were those people who visited those health institutions for HIV counseling and testing purposes during the study period. The classification of cases and controls were based on sero status of those people tested for HIV. Those people with HIV sero positives were designated as cases and those with HIV sero negatives were designated as controls.

A sample size of 227 cases and 726 controls were calculated using the methods of "difference between population proportions" with $80 \%$ power, $95 \%$ confidence level, and a ratio of cases to controls $r$ being $1: 3$, assuming that the prevalence of substance abuse among HIV sero-positive people is 54\%.

People who were 15 years and above, those who came for HIV counseling and testing purpose, who were HIV seropositives and volunteer to participate in the study were considered as cases, while people who were 15 years and above, who came for HIV counseling and testing purpose, and were HIV seronegatives and volunteer to participate in the study were considered as controls.

People whose age was below 15 years, whose serum HIV test result was in the gray zone and those who were nonvolunteer to participate in the study were excluded from the study.

Data were collected during the pre test counseling and before the serostatus of the individuals was known. The collection of data continued until the required number of cases were identified. All HIV seronegative individuals during the same period were included as controls. Data were collected using structured questionnaires. Data collectors were counselors from the respective health institutions who were trained on the procedures. The designed questionnaire was translated first into the local/national language (Amharic) and back translated to English to ensure its consistency. The questionnaires were pretested in similar settings two weeks before the actual data collection. The collected data were checked for completeness, accuracy, clarity and consistency by a supervisor and the principal investigator on daily basis. Any error or ambiguity and incompleteness were corrected before the individual was told the test result in his/her visit for the posttest counseling.

HIV sero status (HIV seropositivity, or seronegativity) was considered as the outcome or dependent variable, while socio demographic variables (age, sex, residence, religion, ethnicity), socio economic variables (income, occupation), and risky behaviors (number of sexual partners, substance use, its type, amount, frequency and history of sexually transmitted diseases) were considered as independent variables.

The collected data was entered using EPI-info version 6.4 statistical package. Analysis was carried out using EPIinfo version 6.4 and SPSS version 10 software. Proportions, percentages, and graphs were used for description of the data as appropriate. Odds ratio with confidence intervals were computed to assess the presence and degree of association between HIV sero 
status and its determinant. P-value of 0.05 was set as a cut-off point for the significance of the association between dependent and independent variables. Logistic regression was used to control for the confounding variables.

Ethical clearance was obtained from relevant bodies and authorities. During the interview, each individual was told about the aim of the study and on the possible benefit of the study and informed consent was obtained from each respondent. The result was confidential and the secrecy of respondents was kept because of the anonymity and double blind nature of the data collection. Respondents were offered health education on the negative effects of substance abuse and were counseled on HIV/AIDS transmission and prevention methods during posttest counseling.

\section{Results}

Of the total population who has visited the study sites between December 2001 and February 2002, 989 participants were eligible for the study. From those, 953 (96.3\%) of the participants completed the interview. Among those, 227 (22.9\%) were cases and 726 (73.4\%) were controls. Nine per cent of the cases and $2.1 \%$ of the controls refused to participate in the study. Males were $336(35.3 \%)$ and females were 617 (64.7\%). Socio demographic characteristics of the study subjects are presented in Table 1.

Table 1: Socio demographic characteristics of study subjects, Addis Ababa, 2002.

\begin{tabular}{|c|c|c|c|}
\hline Characteristics & $\begin{array}{l}\text { HIV Positives }(n=227) \\
\text { No. }(\%)\end{array}$ & $\begin{array}{l}\text { HIV Negatives }(n=726) \\
\text { No. }(\%)\end{array}$ & $\begin{array}{l}\text { Total }(n=953) \\
\text { No. }(\%)\end{array}$ \\
\hline \multicolumn{4}{|l|}{ Sex } \\
\hline Male & $81(35.7)$ & $255(35.1)$ & $336(35.3)$ \\
\hline Female & $146(64.3)$ & $471(64.9)$ & $617(64.7)$ \\
\hline \multicolumn{4}{|l|}{ Age (in years) } \\
\hline $15-19$ & $8(3.50)$ & $75(10.3)$ & $83(8.70)$ \\
\hline $20-24$ & $47(20.7)$ & $310(42.7)$ & 357 (37.5) \\
\hline $25-29$ & $75(33.0)$ & $197(27.1)$ & $272(28.5)$ \\
\hline $30-34$ & $50(22.0)$ & $68(9.40)$ & $118(12.4)$ \\
\hline $35-39$ & $25(11.0)$ & $48(6.60)$ & $73(7.70)$ \\
\hline $40-44$ & $11(4.80)$ & $17(2.30)$ & $28(2.90)$ \\
\hline $45-49$ & $4(1.80)$ & $10(1.40)$ & $14(1.50)$ \\
\hline 50 and above & $7(3.10)$ & $1(0.10)$ & $8(0.80)$ \\
\hline \multicolumn{4}{|l|}{ Educational status } \\
\hline Illiterate & $21(9.30)$ & $23(3.20)$ & $44(4.60)$ \\
\hline Read and write & $7(3.10)$ & $6(0.80)$ & $13(1.40)$ \\
\hline Grade 1-6 & $31(13.7)$ & $56(7.70)$ & $87(9.10)$ \\
\hline Grade 7-8 & $31(13.7)$ & $89(12.3)$ & $120(12.6)$ \\
\hline Grade 9-12 & $109(48.0)$ & $428(59.0)$ & $537(56.3)$ \\
\hline Above grade 12 & $28(12.3)$ & $124(17.1)$ & $152(15.9)$ \\
\hline \multicolumn{4}{|c|}{ Religion of respondents } \\
\hline No religion & $3(1.30)$ & $3(0.40)$ & $6(0.60)$ \\
\hline Orthodox & $195(85.9)$ & $558(76.9)$ & $753(79.0)$ \\
\hline Protestant & $18(7.90)$ & $95(13.1)$ & $113(11.9)$ \\
\hline Catholic & $1(0.40)$ & $3(0.40)$ & $4(0.40)$ \\
\hline Moslem & $10(4.40)$ & $63(8.70)$ & $73(7.70)$ \\
\hline Others & $0(0.00)$ & $4(0.60)$ & $4(0.40)$ \\
\hline \multicolumn{4}{|l|}{ Residence/Address } \\
\hline Addis Ababa & $192(84.6)$ & $590(81.3)$ & $728(82.1)$ \\
\hline Out side Addis & $35(15.4)$ & $136(18.7)$ & $171(17.9)$ \\
\hline \multicolumn{4}{|l|}{ Marital status } \\
\hline Ever married & $131(57.7)$ & $137(18.9)$ & $268(28.1)$ \\
\hline Never married & $96(42.3)$ & $589(81.1)$ & 685 (71.9) \\
\hline
\end{tabular}

The mean $( \pm$ SD) age of the cases was $29.5 \pm 7.4$ years, while that of the controls was $25.5 \pm 6.4$ years. Only 44 $(4.6 \%)$ of the study population was illiterate and the majority of the study population (72.2\%) have educational level of grade 9 and above. Ethnically, 518 $(54.4 \%)$ of the study participants were Amharas followed by Oromos, which were $198(20.8 \%)$. The majority of the study participants $(79.0 \%)$ were followers of the Orthodox religion. About $82 \%$ of the study participants reside in Addis Ababa, $18 \%$ were from out side Addis Ababa and the majority of the study populations (72\%) were never married. Nearly half of the study participants 
(50.2\%) were jobless. Five hundred seventy five $(60.3 \%)$ of the respondents have no private income and 363 $(38.1 \%)$ of the respondents did not know their family income.

Comparison of cases and controls with regard to socio demographic variables has been done. While there was no difference between cases and controls with regard to sex and residence, there was a difference between cases and controls with regard to age, educational status, marital status and religion, $\mathrm{P}$-value $<0.01$.

The overall prevalence of HIV among those people visiting HIV counseling and testing centers was found to be $25.1 \%(n=248)$.

The majority of the cases 125 (55.1\%) drank alcohol in the past one year and the overall prevalence of alcohol use among people visiting HIV testing and counseling centers in Addis Ababa was found to be 429 (45.0\%). The prevalence of khat use is more than twice as high among the cases as in the controls, $72(31.7 \%)$ versus $104(14.3 \%)$. Among substances used cannabis is the drug most tried by the cases in the past one year 6 $(2.6 \%)$.

Respondents were asked on whether alcohol drinking could increase their sexual desire or not. Ninety three of the total $125(74.4 \%)$ of HIV seropositive individuals who drank alcohol acknowledged that alcohol intake increases their sex desire compared to only $42.8 \%$ (133 out of 304) of HIV seronegative drinkers.

Respondents were categorized as heavy drinkers and chewers and light drinkers and chewers based on the frequency and amount of alcohol and khat intake. The odds of serum HIV positivity among "heavy" drinkers and "light" drinkers were 4.83 and 1.57 times as high as the odds of non-drinkers, respectively. Similarly, the odds of serum HIV positivity among "heavy" chewers and "light" chewers were 7.02 and 2.22 times as high as the odds of non-chewers (Table 2).

Table 2: Distribution of respondents by intensity of alcohol drinking and khat chewing in HIV counseling and testing centers in Addis Ababa, 2002

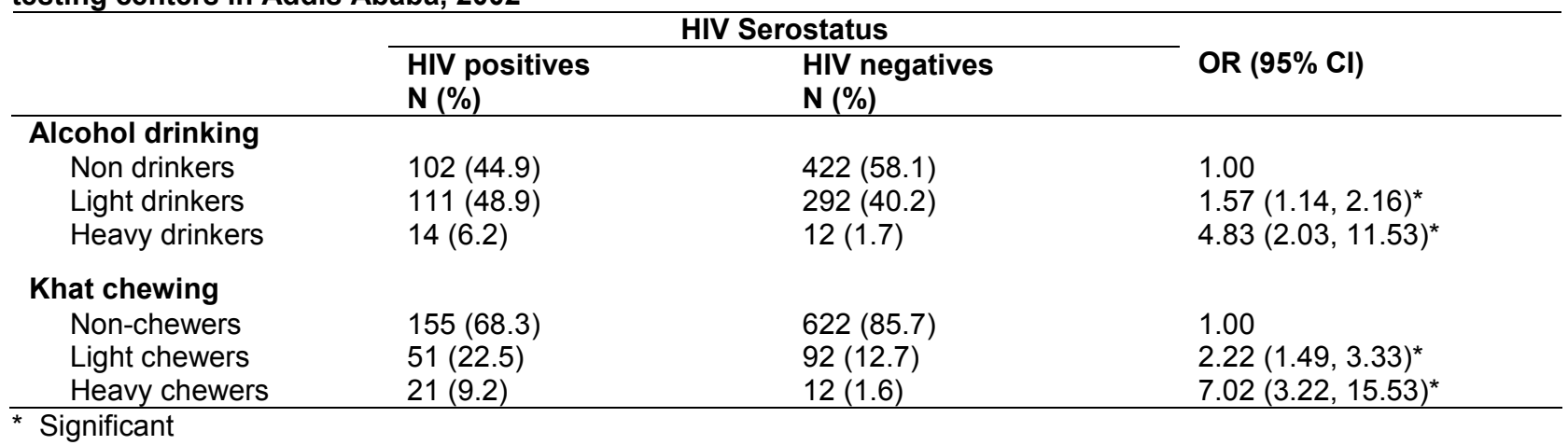

The unmatched case-control analysis was done on 227 cases and 726 controls that completed the interview. Cases and controls were compared by age, sex, educational level, marital status, monthly income and occupation, substance abuse (alcohol drinking, khat chewing, use of "hard" drugs), and ever use of condom. Age 25 years and above, ever use of "hard" drugs, ever drinking alcohol and khat chewing were positively and significantly associated with HIV seropositivity in the bivariate analysis. On the other hand, age of 15-24 years, educational level of grade seven and above, being single, having monthly income and ever use of condom were negatively and significantly associated with serum HIV positivity in the bivariate analysis. Sex of the respondents, having private monthly income, having occupation and illiteracy and primary education or less, however, were not significantly associated with HIV positive sero status in the bivariate analysis (Table 3 ).

Study participants were assessed on their knowledge about the use of condoms, types of sexually transmitted diseases (STDs), and HIV transmission and prevention methods. Respondents were designated as knowledgeable in that specific situation if he/she mentioned three uses of condoms correctly, four types of STDs included in the questionnaire correctly, five methods of HIV transmission and three methods of HIV prevention correctly.

Seven-hundred twenty-seven $(76.3 \%)$ of the respondents have correctly answered the three uses of condoms (20.1\% of the cases Vs $56.2 \%$ of the controls). One hundred seventy-four $(76.7 \%)$ of the cases and 482 $(66.4 \%)$ of the controls have correctly answered four types of sexually transmitted diseases that were included in the questionnaire. Only $94(41.4 \%)$ of the cases and $279(38.4 \%)$ of the controls knew all five methods of HIV transmission included in the questionnaire. However, $178(78.4 \%)$ of the cases and $552(76 \%)$ of the controls knew the three methods of HIV prevention included in the questionnaire. 
Table 3: Variables evaluated, for possible association, with HIV sero status among people visiting HIV counseling and testing centers in Addis Ababa, 2002

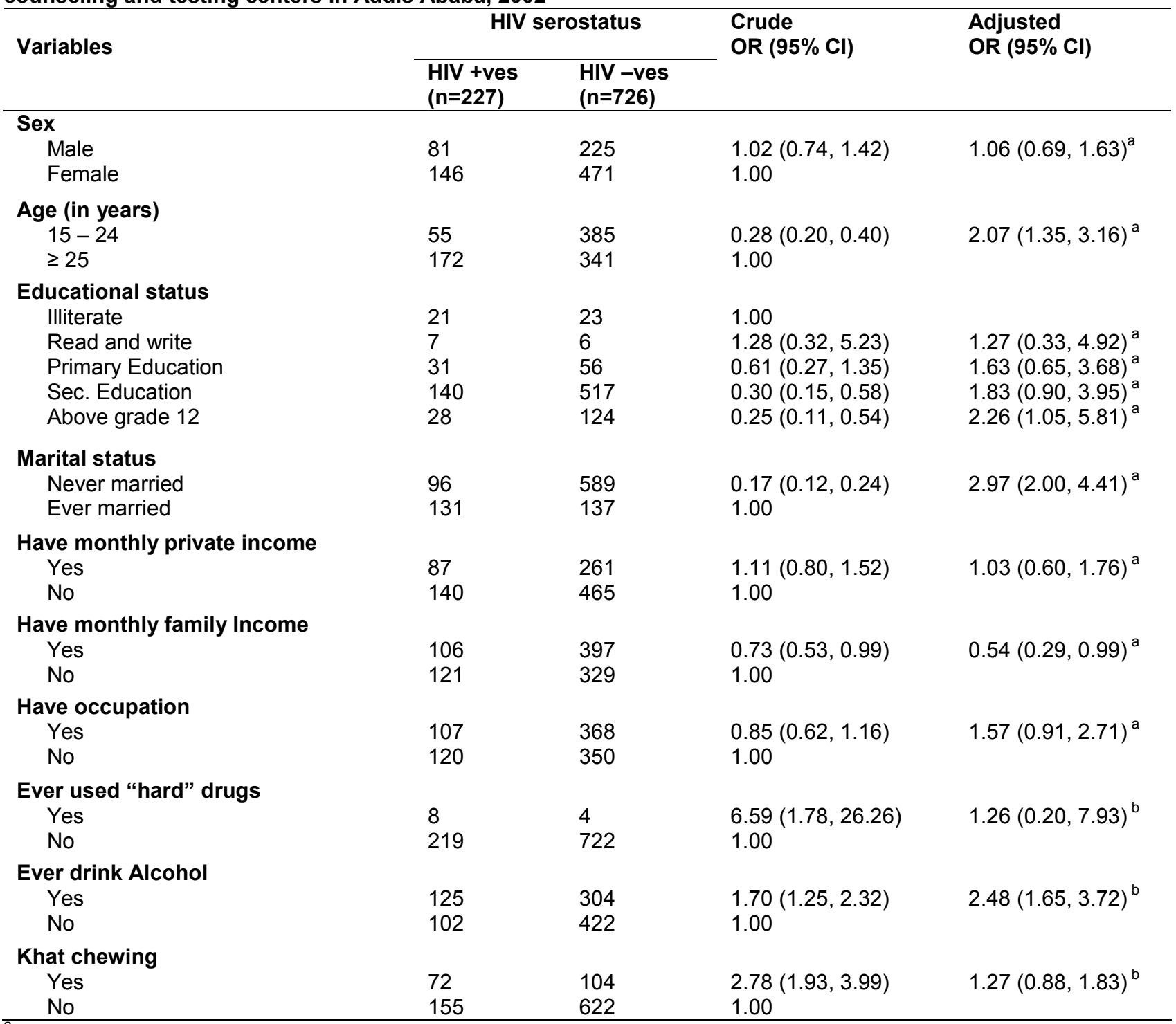

adjusted for socio demographic variables

${ }^{\mathrm{b}}$ Adjusted for variables of substance abuse and condom use

Khat chewing was positively and significantly associated with male sex, having monthly private income, having job, ever drinking alcohol, ever use of condom and having sex with commercial sex workers in the bivariate analysis. However, only male sex, being single and having sex with commercial sex workers were positively associated with khat chewing in logistic regression after controlling for possible confounding variables. Table 4 shows both the crude and adjusted odds ratios of the association of khat chewing and different exposure variables.

Ever drinking alcohol was significantly and positively associated with male sex, having occupation, ever use of condom, having sexual intercourse with commercial sex workers and khat chewing in the bivariate analysis.
However, after controlling for confounding variables in the logistic regression, male sex, having no monthly private income and having sex with commercial sex workers were found to be significantly and positively associated with ever drinking alcohol. Table 5 shows both the crude and adjusted odds ratios of the association of alcohol drinking and different exposure variables.

\section{Discussion}

HIV/AIDS is the major problem and a big challenge to the world today. It is an obstacle to both the health and development of people in the world. Its combination with substance abuse including drugs and alcohols - a devastating combination, had further aggravated the situation and facilitated its transmission $(1,4)$. 
Table 4: Association of different variables with Khat chewing among people visiting HIV counseling and testing centers in Addis Ababa, 2002.

\begin{tabular}{|c|c|c|c|c|}
\hline \multirow{2}{*}{ Variables } & \multicolumn{2}{|c|}{ Khat chewed } & \multirow{2}{*}{$\begin{array}{l}\text { Crude } \\
\text { OR }(95 \% \mathrm{CI})\end{array}$} & \multirow{2}{*}{$\begin{array}{l}\text { Adjusted } \\
\text { OR }(95 \% \mathrm{Cl})\end{array}$} \\
\hline & Yes & No & & \\
\hline \multicolumn{5}{|l|}{ Sex } \\
\hline Male & 90 & 246 & $2.26(1.60,3.19)$ & $2.35(1.56,3.53)$ \\
\hline Female & 86 & 531 & & \\
\hline \multicolumn{5}{|l|}{ Age (in years) } \\
\hline $15-24$ & 69 & 371 & $0.71(0.50,1.00)$ & $1.02(0.68,1.52)$ \\
\hline$\geq 25$ & 107 & 406 & & \\
\hline \multicolumn{5}{|l|}{ Educational status } \\
\hline Illiterate & 3 & 41 & 1.00 & \\
\hline Read and write & 5 & 8 & $8.54(1.37,59.1)$ & $0.13(0.02,0.65)$ \\
\hline Primary Education & 21 & 66 & $4.35(1.13,19.6)$ & $0.28(0.08,0.99)$ \\
\hline Sec. Education & 117 & 540 & $2.96(0.86,12.2)$ & $0.34(0.10,1.14)$ \\
\hline Above grade 12 & 30 & 122 & $3.36(0.91,14.6)$ & $0.36(0.10,1.29)$ \\
\hline \multicolumn{5}{|l|}{ Marital status } \\
\hline Ever married & 63 & 205 & & \\
\hline Never married & 113 & 572 & $0.64(0.45,0.92)$ & $1.58(1.05,2.38)$ \\
\hline \multicolumn{5}{|c|}{ Have monthly private income } \\
\hline Yes & 78 & 270 & $1.49(1.06,2.11)$ & $0.96(0.59,1.58)$ \\
\hline No & 98 & 507 & & \\
\hline \multicolumn{5}{|c|}{ Have monthly family Income } \\
\hline Yes & 153 & 690 & $0.84(0.50,1.41)$ & $1.27(0.76,2.13)$ \\
\hline No & 23 & 87 & & \\
\hline \multicolumn{5}{|l|}{ Has occupation } \\
\hline Yes & 104 & 371 & $1.58(1.12,2.23)$ & $1.03(0.62,1.72)$ \\
\hline No & 72 & 406 & & \\
\hline \multicolumn{5}{|l|}{ Ever drink Alcohol } \\
\hline Yes & 123 & 306 & $3.57(2.47,5.16)$ & $1.62(0.81,3.26)$ \\
\hline No & 53 & 471 & & \\
\hline \multicolumn{5}{|l|}{ Ever used condoms } \\
\hline Yes & 88 & 236 & $1.61(1.12,2.31)$ & $0.76(0.41,1.40)$ \\
\hline No & 79 & 341 & & \\
\hline \multicolumn{5}{|l|}{ Sex with CSW } \\
\hline Yes & 24 & 20 & $3.34(1.65,7.20)$ & $2.95(1.45,5.99)$ \\
\hline No & 46 & 132 & & \\
\hline
\end{tabular}

The estimated adult HIV prevalence in Ethiopia in 2001 and 2003 are $6.6 \%$ and $4.4 \%$, respectively (AIDS in Ethiopia 2002 and 2004). The current study has revealed that the overall prevalence of HIV among individuals aged 15 years and above visiting HIV counseling and testing centers is $25.1 \%$, which is higher than the prevalence in the general population. The high prevalence of HIV among these people cannot be a surprise either because majority of these people came to the testing centers to know their status or because they suspected themselves, $626(65.7 \%)$ and $140(15.7 \%)$, respectively. Thus, these are self selected people, probably who were involved in some form of risky activities that had exposed them to HIV infection.

Similar to other African countries (36), majority of the people visiting HIV counseling and testing centers in this study were shown to be young people aged 20 to 29 years old which accounted for about two-third of the total study populations. This high number of young people visiting the testing centers indicates that this group might have suspected themselves that they acquire the infection and wanted to know their serum status. This group also needs to work abroad as they have no job in the country in which case they need to be tested.

In countries where HIV prevalence is high and where there are numerous deaths attributed to AIDS, it is common for many to develop feelings of hopelessness and a misconception that behavioral change is futile. In these settings, the power of positive behavioral change messages may be reinforced by effective HIV counseling and testing services (36). The high rate $626(65.7 \%)$ of respondents visiting HIV counseling and testing centers to know their own status might indicate the increased need for voluntary counseling and testing (VCT) in Ethiopia. 
Table 5: Association of different variables with ever drinking alcohol among people visiting HIV counseling and testing centers in Addis Ababa, 2002.

\begin{tabular}{|c|c|c|c|c|}
\hline \multirow{2}{*}{ Variables } & \multicolumn{2}{|c|}{ Alcohol Drink } & \multirow{2}{*}{$\begin{array}{l}\text { Crude } \\
\text { OR (95\% Cl) }\end{array}$} & \multirow{2}{*}{$\begin{array}{l}\text { Adjusted } \\
\text { OR (95\% CI) }\end{array}$} \\
\hline & Yes & No & & \\
\hline \multicolumn{5}{|l|}{ Sex } \\
\hline Male & 210 & 126 & $3.03(2.28,4.03)$ & $2.77(1.99,3.84)$ \\
\hline Female & 219 & 398 & & \\
\hline \multicolumn{5}{|l|}{ Age (in years) } \\
\hline $15-24$ & 173 & 267 & $0.65(0.50,0.85)$ & $1.05(0.78,1.43)$ \\
\hline$\geq 25$ & 256 & 257 & & \\
\hline \multicolumn{5}{|l|}{ Educational status } \\
\hline Illiterate & 21 & 23 & 1.00 & \\
\hline Read and write & 8 & 5 & $1.75(0.42,7.46)$ & $0.58(0.16,2.12)$ \\
\hline Primary Education & 39 & 48 & $0.89(0.40,1.96)$ & $1.44(0.68,3.06)$ \\
\hline Sec. Education & 278 & 379 & $0.80(0.42,1.54)$ & $1.38(0.73,2.62)$ \\
\hline Above grade 12 & 83 & 69 & $1.32(0.64,2.27)$ & $1.16(0.57,2.38)$ \\
\hline \multicolumn{5}{|l|}{ Marital status } \\
\hline Never married & 295 & 390 & $076(0.56,1.01)$ & $1.29(0.92,1.80)$ \\
\hline Ever married & 134 & 134 & & \\
\hline \multicolumn{5}{|c|}{ Have monthly private income } \\
\hline Yes & 16 & 14 & $1.41(0.65,3.10)$ & $0.71(0.47,0.96)$ \\
\hline No & 413 & 510 & & \\
\hline \multicolumn{5}{|c|}{ Have monthly family Income } \\
\hline Yes & 384 & 459 & $1.21(0.79,1.85)$ & $0.98(0.64,1.50)$ \\
\hline No & 45 & 65 & & \\
\hline \multicolumn{5}{|l|}{ Has occupation } \\
\hline Yes & 254 & 221 & $1.99(1.52,2.60)$ & $1.05(0.70,1.58)$ \\
\hline No & 175 & 303 & & \\
\hline \multicolumn{5}{|l|}{ Khat chewed } \\
\hline Yes & 123 & 53 & $3.57(2.47,5.16)$ & $1.62(0.80,3.25)$ \\
\hline No & 306 & 471 & & \\
\hline \multicolumn{5}{|l|}{ Ever used condoms } \\
\hline Yes & 197 & 127 & $1.88(1.38,2.55)$ & $0.68(0.37,1.24)$ \\
\hline No & 190 & 230 & & \\
\hline \multicolumn{5}{|l|}{ Sex with Csw } \\
\hline Yes & 38 & 6 & $3.06(1.15,8.57)$ & $2.40(1.03,6.21)$ \\
\hline No & 120 & 58 & & \\
\hline
\end{tabular}

As high as $268(28.1 \%)$ of the respondents reported that visa application was their primary reason to visit HIV counseling and testing centers. The purpose of visa application is to find a job abroad. This is also consistent with our finding because most of our respondents were jobless or did not have monthly income of their own, 478 $(50.2 \%)$ Vs 575 (60.3\%), which could be their main reason for seeking job abroad.

HIV transmission by non-sterilized injecting equipment and intravenous drug use has not been documented as a major mode of HIV transmission in Africa. Unlike the developed countries where up to $30 \%$ of HIV infected individuals are IVDUs or have had sexual contact with IVDUs, injectable drugs are not commonly used in Africa (17). The present study also supports that since no case of HIV seropositive has reported use of injectable drugs.
Drug abuse has been incriminated as a potential exposure factor to HIV/AIDS by causing loss of inhibition and involvement in risky sexual behaviors, such as unprotected sex, multiple sexual partners, prolonged and traumatic sex, and risky injections $(4,5,7,19)$. More than $74 \%$ of HIV seropositives in this study have acknowledged that alcohol drinking increases their sex desire, which might be responsible for their exposure to HIV infection. This finding is similar to studies done in USA where many people have reported being involved in sexual act after consuming alcohol $(10,31)$.

In this study, the use of substances such as khat, alcohol and other "hard" drugs were found to be significantly associated with serum HIV positivity in bivariate analysis. However, after controlling for confounding variables, the association of ever use of "hard" drugs with serum HIV positivity was found to be insignificant. 
This might be due to few numbers of respondents who acknowledged the use of "hard" drugs in our study populations. The possible explanation for this could be under-reporting of the use of these substances by the cases because of cultural and legal issues or could be due to recall bias.

Khat chewing in some areas occurs together with the use of other substances such as alcohol and indulging in alcohol is common among people with sleep disturbances following khat chewing $(12,28)$. A significant association of khat chewing with HIV seropositivity in the bivariate analysis, which disappears when controlled for other variables in the present study, might be due to confounding by alcohol intake that usually occurs following khat chewing. On the other hand, the prevalence of male impotence among Somali and Djiboutian khat chewers was reported to be as high as $60 \%$ (28). Similarly, a study in Ethiopia has shown a significant association of sexual dysfunction with intensity of khat chewing with the risk being higher among daily users (28). Thus, the lack of significant association of khat chewing and serum HIV positivity, when controlled for alcohol intake, in the present study supports those earlier findings of reduced desire for sex among khat chewers. This implies that khat chewing alone may not predispose to risky sexual behaviors and hence to HIV infection unless alcohol is indulged in following khat chewing.

Our study revealed that khat chewing was positively associated with alcohol drinking in the bivariate analysis. This is similar to an earlier finding where current khat chewing was positively associated with alcohol drinking (28). Concomitant use of khat and alcohol could probably be one of the risk factors for exposure to HIV infection. This study indicated that people who were both drinkers and chewers were 6 times more likely to be HIV seropositives compared to both non-drinkers and nonchewers.

Alcohol and drug use by young people may lead to earlier sexual initiation, unprotected sexual intercourse and multiple partners as well as putting young people at risk for HIV/AIDS infection, unintended pregnancy, and sexual violence $(10,22)$. The most frequent users of illicit drugs are jobless youths and street children (21). The higher rate of serum HIV positivity in young people aged 15 to 24 years in our study raises our suspicion of the use of such drugs by the cases and the involvement of those groups in some high-risk activity, which predisposed them to HIV infection.

The most unusual characteristic of AIDS among Africans are the equal distribution of cases between men and women and the high frequency of cases being among commercial sex workers and their clients. In contrast to the industrialized world where the epidemic is reported to be entrenched among homosexual men and injecting drug users, with little or no evidence for this pattern in Africa (37). The present study is consistent with this fact in that there was no significant sex difference in serum HIV status and no injecting drug was associated with serum HIV positivity.

One of the prime slogans of the anti HIV/AIDS activists to prevent HIV infection and spread in a population is being one-to-one primarily through marriage and marriage is known to be a protective factor against HIV infection. The present study also supported that reality.

Surprisingly, a statistically significant number of people with educational level of above grade 12 were found to be HIV seropositives. This is against the fact that people that are more knowledgeable could take care of HIV infection, as they easily understood both the transmission and prevention methods. However, knowledge alone, as seen in this study, may not be protective unless behavioral change is attained.

The present study showed that being male, having job, khat chewing, ever use of condom and having sex with commercial sex workers were related to ever intake of alcohol. After controlling for possible confounders, only male sex, having no private income and having sex with commercial sex workers were found to be significantly associated with ever intake of alcohol. Similarly, being male, single and having sex with commercial sex workers were factors significantly related to khat chewing after controlling for other confounding variables. Unlike earlier findings $(7,21)$ the present study could not identify being young and joblessness as factors related to substance abuse. This might be due to underreporting by the users or because of recall bias.

Government and other responsible bodies should design a strategy to control the use of substances like alcohol, which were found to be responsible for the spread of HIV infection. Emphasis should be on behavioral change to prevent HIV infection, as knowledge alone does not help to combat the epidemic. There should be strong commitment from government and other responsible bodies to discourage the flourishing advertisement of alcoholic drinks in the mass medias. Community based study needs to be carried out to identify the true prevalence of substance abuse in Ethiopia. Wide range prospective study needs to be conducted to explore into the association between substance abuse and HIV infection in Ethiopia.

\section{References}

1. UNAIDS/WHO, AIDS epidemic update, December 2001, UNAIDS/WHO 2001, Geneva, Switzerland.

2. Pathfinder International, Integrating STD/HIV/AIDS services with $\mathrm{MCH} / \mathrm{FP}$ programs, a guide for policy makers and program managers, 2000.

Ethiop.J.Health Dev. 2005;19(2) 
3. MOH, AIDS in Ethiopia, Disease Prevention and Control Department, Ministry of Health, third Edition, November 2000.

4. UNAIDS, Drug abuse and HIV/AIDS: A devastating combination, UNAIDS.

5. Drug use and HIV/AIDS, UNAIDS statement presented at the UN General Assembly Special Session on Drugs, UNAIDS, 1999, Geneva.

6. Seth F. Berkley, Public health measures to prevent HIV spread in Africa: In AIDS in Africa, New York, USA 1994:473-495.

7. WHO, Women and Substance: In program on substance abuse, 1993 Country assessment report, WHO, 1993.

8. WHO, Alcohol and Public Health in Eight Developing Countries, Substance Abuse department, WHO, Geneva, 1999.

9. $\mathrm{MOH}$, Health and Health Related Indicators, Planning and Programming Department, Health Information Processing and Documentation Team, MOH, 2001.

10. Kaiser Family Foundation, Substance Use and Risky Sexual Activity, Menlo Park, CA: The Henry J Kaiser Family Foundation, Feb. 2002.

11. John L. Martin, Drinking Pattern, and Drinking Problems in a community sample of Gay men, Division of Sociomedical Science, Colombia University School of Public Health, New York, 1990:27-34.

12. Mesfin K., Hassen T. Sherief, Ghimja F. and Teshome T. Drug use among High School Students in Addis Ababa and Butajira, EJHD, 1999;13(2):101-106.

13. Manuel Carballo and Patrick I. Kenya, Behavioral Issues and AIDS: In AIDS in Africa, New York, USA 1994: 497-512.

14. Leggett T, Crack, sex work and HIV, AIDS Analysis Africa, Apr-May 1999;9(6).

15. Seyoum G, Ayalew G. A report on rapid assessment of the situation of drug and substance abuse in selected urban areas in Ethiopia. Prepared for $\mathrm{MOH}$ and UNDP, November 1995.

16. John R. M. Caplehorn and John B. Saunders, Factors Associated with heroin users' AIDS risk taking Behaviors, Australian J Public Health, 1999;17:1317.

17. Henry L. Francis and Thomas C. Quinn, Blood Born Transmission of HIV in Africa: In Aids in Africa, New York 1994: 237-249.

18. Des Jarlais DC, Friedman SR, AIDS and Use of Injected Drugs, Scientific American, 1994:82-8.

19. Louis D. Saravolatz, Robert F. Cerra, Donald J. Pohlod and Susan Smereck, The effect of Alcohol on HIV infection in Vitro: Alcohol, Immunomodulation, and AIDS, Alan R. Liss, Inc, 1990:267-271.

20. M. Gossop, B. Powis, P. Griffiths, and J. Strang, Female Prostitutes in South London: Use of Heroin,
Cocaine, Alcohol and their relationship to health risk behaviors, Drug Transition Project, National Addiction Center, Maudsley Hospital, London, UK, 1995;7(3):253-260.

21. Mesfin K, Hassen T. S, Ghimjha F, Teshome T. Knowledge of "drug" use and associated factors as perceived by health professionals, farmers, the youth and law enforcement agencies in Ethiopia, EJHD; August 1999;13(2): 141-150.

22. Kaiser Family Foundation, Substance Use and Risky Sexual Behavior: Attitudes and Practices Among Adolescents and Young Adults, Menlo Park, CA: The Henry J Kaiser Family Foundation, Feb. 2002.

23. Ron Stall, The prevention of HIV infection Associated with Drug and Alcohol use during Sexual Activity: In AIDS and Substance Abuse, the center for AIDS prevention studies, University of California, San Francisco, 1988:73-88.

24. Barry Stimmel, AIDS, Alcohol and Heroin, A Particular deadly Combination: In Advances in Alcohol and Substance Abuse, Spring 1987;63 (3).

25. Barbara VanOss Marin, Elena Flores, Acculturation, Sexual Behavior, and Alcohol Use among Latinas: In International Journal of the Addiction, 1994;29(9):1101-1114.

26. Robert E. Booth, John K. Watters and Dale D. Chitwood, HIV risk related Sex Behaviors among Injection Drug Users, Crack Smokers, and Injection Drug Users who Smoke Crack, Am J Public Health, 1993;83(8):1144-1148.

27. Arif, Health care for the prevention of drug and Alcohol Dependence: In Report of Six-World Congress for the Prevention of Alcoholism and Drug Dependency, International Commission for the Prevention of Alcoholism and Drug Dependency, Washington DC, USA, 1986:28-32.

28. Mesfin Belew, Dereje Kebede, Mesfin Kassaye, and Fikre Enqouselassie, The Magnitude of Khat Use and its Association with Health, Nutrition, and Socioeconomic Status, EMJ,2000; VOL 38(1):1126.

29. Joseph Westermeyer, Marvin Seppala, Shelly Gasow, and Gregory Carlson, AIDS-Related Illness and AIDS Risk in Male Homo/Bisexual Substance Abusers: Case Report and Clinical Issue, Am J Drug Alcohol Abuse, 1989;15 (4):443-461.

30. Barbara G. Faltz, Scott Madover, Treatment of Substance Abuse in Patients with HIV infection: In AIDS and Substance Abuse, San Francisco AIDS Professional Project, 1988:143-157.

31. Kral AH; Molnar BE; Booth RE; Watters JK, Prevalence of sexual risk behavior and substance use among runaway and homeless adolescents in San Francisco, Denver, and New York City, International Journal of STD \& AIDS 1997;8(2):109-17.

32. I.W. Fong, S. Read, M.A. Wainberg, W.K. Chia, and C. Major, Alcoholism and Rapid Progression to 
AIDS after Seroconversion, Clinical infectious Diseases, 1994;19:337-338.

33. CSA, Demographic and Health Survey Ethiopia 2000, Central Statistic Authority, 2001.

34. Gerond Lake-Bakkar and Roger Grimson, Alcohol Abuse and Stage of HIV Disease in intravenous drug abusers, Journal of the Royal Society of Medicine, 1996;89:389-392.

35. Harvey A. Siegel, R. G. Carlson, R. Falck et al, HIV infection and Risk Behaviors among Intravenous Drug Users in Low Seroprevalence areas in the Midwest, AJPH,1991;81(12):95-113.

36. UNAIDS, Knowledge is Power: Voluntary HIV counseling and testing in Uganda, Joint United Nations Program on HIV/AIDS, 1999:36-37.
37. Thomas C. Quinn AIDS in Africa: a retrospective, Bulletin of the World Health Organization, 2001;79(12):1156-1158.

38. Kefenie H, Desta B, Mengesha S, Zewdie D, Kebede T. Prevalence of HIV-1 antibodies in patients with sexually transmitted diseases, Ethiop Med J 1991;29:63-69.

39. Francis A. Plummer, Mark W. Tyndall, Jackoniah O. Ndinya-Achola, and Stephen Moses. Sexual Transmission of HIVs and the Role of Sexually Transmitted Diseases: In AIDS in Africa, New York, 1994. 

